\title{
The Regulation of Glutamine Metabolism in Candida utilis: Mechanisms of Control of Glutamine Synthetase
}

\author{
By A. P. SIMS, JENNIFER TOONE AND VERONICA BOX \\ School of Biological Sciences, University of East Anglia, Norwich, NOR 88C \\ (Received I 8 March I974; revised 2 May 1974)
}

\begin{abstract}
SUMMAR Y
Methods have been developed which permit the measurement of L-[U-11 C]isoleucine incorporation into glutamine synthetase so that the rate of de novo enzyme synthesis can be measured during enzyme deactivation and reactivation. The results suggest that glutamine, a co-repressor of enzyme synthesis, affects enzyme translation. Pulse labelling experiments indicate that enzyme tetramers are not direct precursors of the active enzyme but instead represent a pool of 'resting' enzyme. 'Fine' control of activity is achieved by reversible aggregation of tetramers, with diminished biosynthetic activity, into active octamers. A number of negative and positive effectors can alter the equilibrium between the two enzyme forms. An earlier suggestion that the monomers produced by the irreversible dissociation of 'tight' enzyme tetramers cannot be re-utilized by the yeast has been confirmed. Proteolytic enzymes do not seem to be directly implicated in the destruction of the enzyme. A model is presented which incorporates all the available information on the control of glutamine biosynthesis in food yeast.
\end{abstract}

\section{IN TRODUCTION}

The regulation of glutamine biosynthesis in food yeast has been shown to rely upon the precise control of enzyme amount and not upon changes of enzyme activity resulting from variable feedback inhibition (Sims \& Ferguson, 1974). Glutamine itself has been implicated in the system of control since it both functions as a co-repressor of enzyme synthesis and can cause rapid enzyme inactivation under conditions where it rapidly accumulates in the organism (Ferguson \& Sims, I974a). Preliminary studies with inhibitors of protein synthesis indicated that enzyme inactivation was an irreversible process and that restoration of catalytic activity required de novo synthesis of enzyme (Ferguson \& Sims, 1974b). This conclusion was questioned, however, by recent work (Sims, Toone \& Box, 1974) which showed that the yeast enzyme is an octameric protein comprising two weakly-bound half molecules; the inactivation of the enzyme in vivo initially involves the dissociation of glutamine synthetase into these tetramers, which have reduced biosynthetic activity. It was also observed that tetramers could reassociate in vitro to form enzyme with normal biosynthetic activity and this suggested a possible mechanism for the fine control of enzyme activity. In the present paper we describe experiments which confirm that this system of control operates in the living organism and establish that metabolic intermediates can directly modify the quaternary structure of the enzyme. 


\section{METHODS}

Candida utilis NCYC737 was grown in batch culture in synthetic medium (Ferguson \& Sims, I97I) at $27^{\circ} \mathrm{C}$ using a Gallenkamp orbital shaker. In one experiment a 21 turbidostat was used (Folkes \& Sims, 1974). In some experiments 'conditioned' medium was used; in these instances contaminating traces of ammonia were removed from the culture as described by Ferguson \& Sims (1974a). Cells were harvested by suction filtration on to Whatman GF/C and the filter pad was frozen in liquid nitrogen. Harvesting was normally completed within $40 \mathrm{~s}$ of sampling. Soluble enzyme extracts were prepared as described by Ferguson \& Sims (197I). In some experiments activities were measured in yeast rendered permeable by freezing in liquid nitrogen (Ferguson \& Sims, 1974a). Glutamine synthetase [L-glutamate: ammonia ligase (ADP), EC. 6.3.I.2] was measured as transferase and synthetase activities (Ferguson \& Sims, 1974a). Both activities remain constant in yeast pads stored at $-20^{\circ} \mathrm{C}$ for 2 weeks. Nitrate reductase (nitrate NADP oxidoreductase, EC. I .6.6.2) was assayed by nitrite formation according to the method of Nason \& Evans (1953). $\alpha$-Glucosidase (EC. 2.4.I.3) was measured by following the hydrolysis of $p$-nitrophenyl- $\alpha$-D-glucopyranoside in $0 . \mathrm{I}$ M-phosphate buffer ( $\mathrm{pH} \mathrm{6.8).}$

Glutamine synthetase was purified as described by Sims et al. (1974) except that the Whatman DE 52 was swollen in $6 \mathrm{M}$-urea and the column $(4 \times 0.9 \mathrm{~cm})$ was packed using the 'fines' fraction.

Measurement of radioactivity, sucrose gradient centrifugation and measurement of nitrogenous compounds in the medium and cell extracts were carried out as described in earlier papers (Sims et al. 1974; Ferguson \& Sims, 1974a).

\section{RESULTS}

\section{Movement of ${ }^{14} \mathrm{C}$ out of and into glutamine synthetase octamers during enzyme deactivation and reactivation}

The objective of these experiments was to assess the extent to which glutamine synthetase reassociates under normal physiological conditions. A typical experiment (Fig. I, Table I) was carried out as follows: an exponentially dividing culture of yeast growing under conditions of repressed enzyme synthesis $(2.8 \mathrm{mM}$-glutamine) was transferred for $30 \mathrm{~min}$ to conditioned medium containing glutamate $(2 \cdot 8 \mathrm{mM}), \mathrm{L}-\left[\mathrm{U}-{ }^{14} \mathrm{C}\right]$ isoleucine $(30 \mu \mathrm{Ci}, 0 \cdot 15 \mathrm{~mm})$ and other nutrients. The rapid synthesis of glutamine synthetase under these conditions (Ferguson \& Sims, 1974b) ensures appreciable incorporation of label into the enzyme. A sample of yeast was removed and the remainder of the culture was transferred to a medium containing glutamine $(2.8 \mathrm{~mm})$. After $30 \mathrm{~min}$ of growth a second sample was taken and the remainder of the yeast was transferred back to glutamate and sampled after $30 \mathrm{~min}$. In a second experiment (Table I) labelled enzyme was deactivated and reactivated for a longer period $(60 \mathrm{~min})$. Glutamine synthetase from these yeast samples was isolated and some of it was purified. Enzyme eluted from the DE 52 column was layered onto a linear (5 to $20 \%$ ) sucrose gradient and centrifuged for about $15 \mathrm{~h}$ at $105000 \mathrm{~g}$. The $15.4 \mathrm{~s}$ octamer was detected by transferase activity and all the fractions from the gradient were assayed for ${ }^{14} \mathrm{C}$ and protein content. The isotope content of the enzyme (expressed as d.p.m./mg protein) was calculated from the transferase activity data assuming the specific activity of the purified glutamine synthetase to be 88.7 units/mg protein. In separate experiments crude protein extracts were fractioned so that the amount of enzyme tetramer could be estimated since this component was lost during enzyme purification (results not shown). 

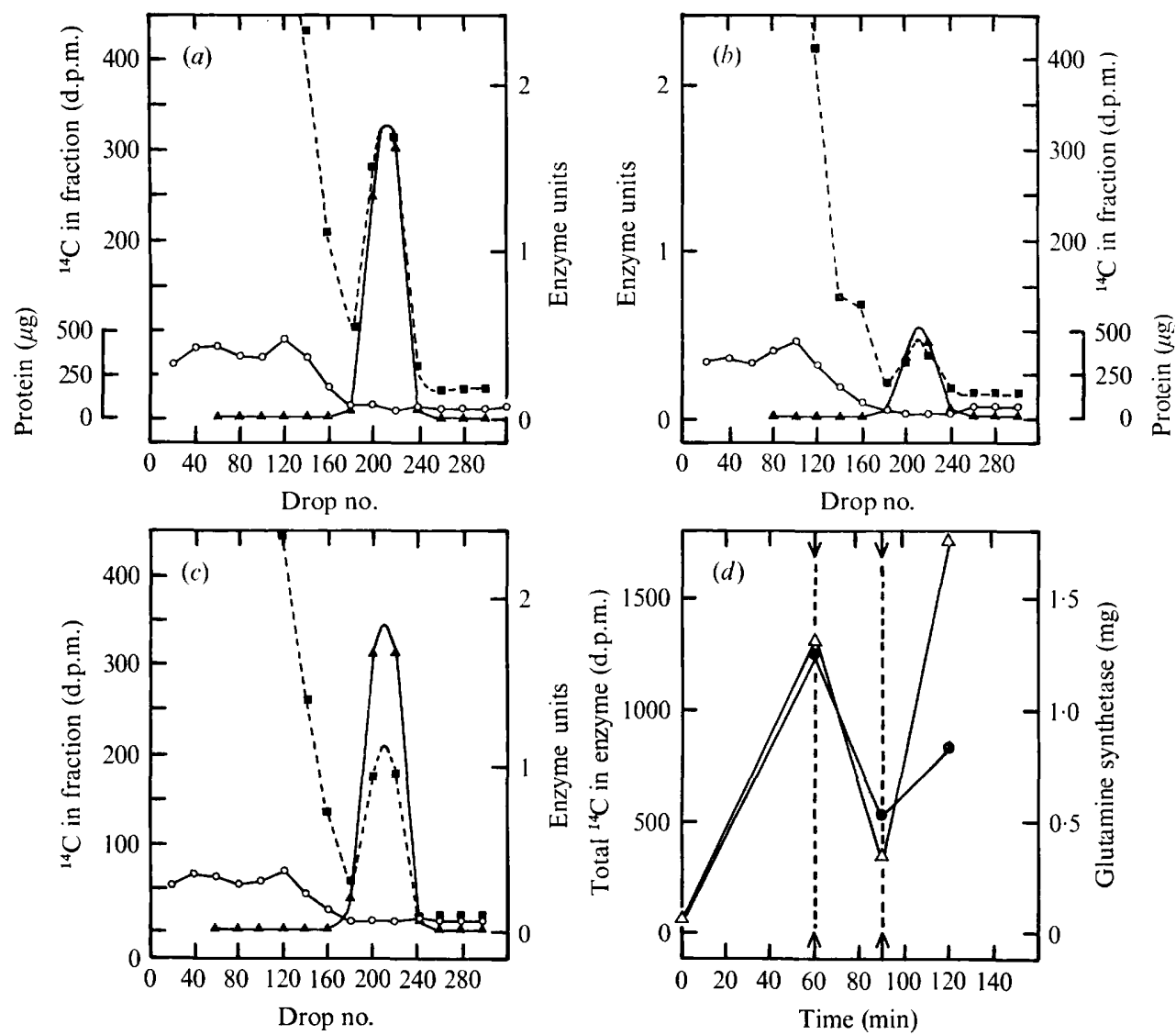

Fig. I. Changes in the ${ }^{14} \mathrm{C}$ content of glutamine synthetase during enzyme deactivation and reactivation. Yeast was pulse labelled with $\left[\mathrm{U}-{ }^{14} \mathrm{C}\right]$ isoleucine and the enzyme deactivated by transferring the culture to an unlabelled medium containing glutamine. The culture was subsequently transferred to glutamate to reactivate the glutamine synthetase. Enzyme was isolated after the different treatments and fractionated so that changes in its ${ }^{14} \mathrm{C}$ content could be measured. (a) Sucrose density centrifugation of partly purified enzyme octamer ( $15.4 s)$ isolated from yeast following $60 \mathrm{~min}$ exposure to isotope. Fractions were assayed for transferase activity $(\boldsymbol{\Delta}),{ }^{14} \mathrm{C}$ content $(\square)$ and protein $(O)$. (b) Changes in transferase activity and ${ }^{14} \mathrm{C}$ content of the octamer after $30 \mathrm{~min}$ deactivation; symbols as in $(a) .(c)$ The return of ${ }^{14} \mathrm{C}$ into the enzyme following reactivation of the enzyme; symbols as in $(a)$. $(d)$ The kinetics of changes in enzyme and its ${ }^{14} \mathrm{C}$ content following 30 min deactivation and reactivation. $\triangle$, Total enzyme; $\bullet$, total ${ }^{14} \mathrm{C}$. An enzyme unit is defined throughout as $\mu \mathrm{mol}$ hydroxamate formed $/ \mathrm{min} / \mathrm{mg}$ protein $\left(30^{\circ} \mathrm{C}\right)$. The arrows indicate the times of deactivation and reactivation.

Three conclusions can be drawn from the results of these experiments (Fig. I and Table I). First, a net movement of ${ }^{14} \mathrm{C}$ tracer into the active enzyme accompanies the reactivation of the enzyme in vivo. Secondly, only about half the counts are in the active octamer following reactivation, which indicates that appreciable irreversible destruction of enzyme accompanies the inactivation of the enzyme under these conditions. Thirdly, it can be calculated from the amount of enzyme tetramer formed, that the net return of ${ }^{14} \mathrm{C}$ into the active enzyme corresponds closely to the complete reassociation of the tetramer remaining in the organism at the time of reactivation. 
Table I. Changes in the $\left[U-{ }^{14} C\right]$ isoleucine content of glutamine synthetase octamer following deactivation and reactivation of the enzyme

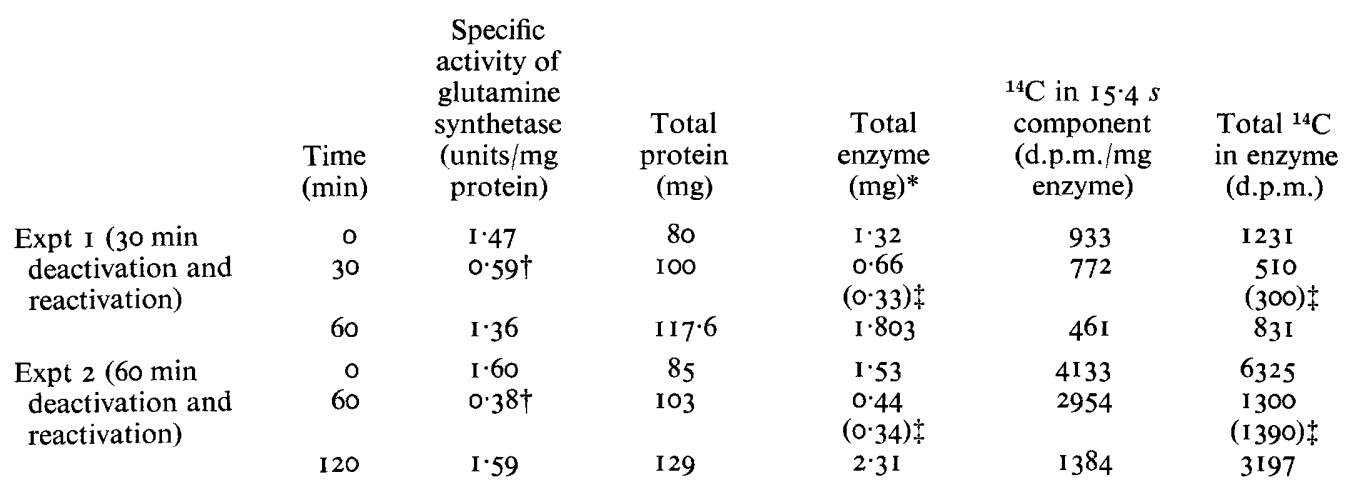

Details of the experiments are given in the text and in Fig. 1 .

* Enzyme activity data were converted to mg glutamine synthetase, assuming a specific activity for the purified enzyme of 88.7 units $/ \mathrm{mg}$ protein. This value supersedes the slightly lower figure quoted by Sims, Toone \& Box (1974).

$\dagger$ Includes an enzyme activity contribution from the $8.7 \mathrm{~s}$ component.

\$ The value in parentheses is calculated from the amount $8.7 \mathrm{~s}$ component measured in this experiment. The contribution of counts in the $8.7 s$ component can be shown to be about 300 d.p.m. in Expt $I$ and about I 390 d.p.m. in Expt 2, assuming the specific transferase activity of the tetramer is half that of the native enzyme.

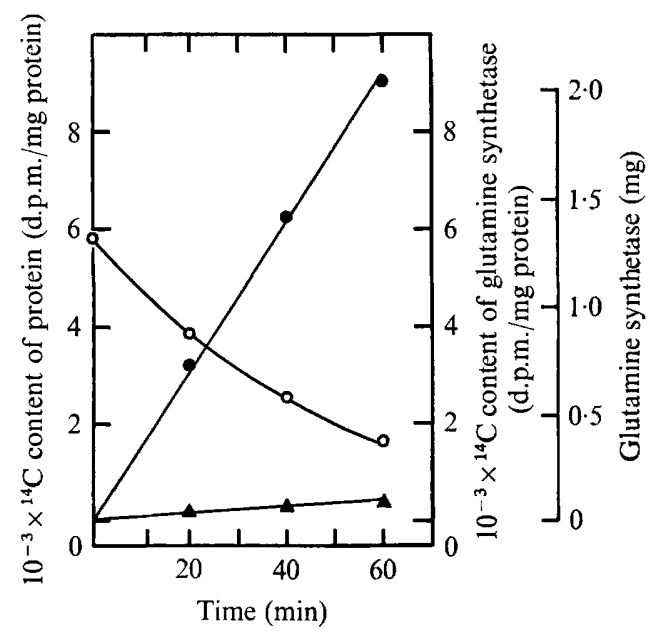

Fig. 2. The kinetics of ${ }^{14} \mathrm{C}$ labelling into glutamine synthetase octamer and 'mixed' proteins during enzyme deactivation. Glutamate-grown yeast was transferred to a medium containing glutamine and $\left[\mathrm{U}-{ }^{14} \mathrm{C}\right]$ isoleucine and harvested at intervals. The enzyme was isolated and changes in its ${ }^{14} \mathrm{C}$ content measured. $\boldsymbol{\Delta}$, Specific activity of glutamine synthetase; $\boldsymbol{O}$, specific activity of 'mixed' proteins; $O$, glutamine synthetase.

\section{Incorporation of ${ }^{14} \mathrm{C}$ into glutamine synthetase octamers during enzyme deactivation}

This experiment was carried out as described in the previous section except that the yeast was initially grown with glutamate $(2.8 \mathrm{~mm})$ as sole source of nitrogen. The experiment was initiated by adding glutamine $(2.8 \mathrm{~mm})$ and $\left[\mathrm{U}-{ }^{14} \mathrm{C}\right]$ isoleucine $(20 \mu \mathrm{Ci}, 0.15 \mathrm{~mm})$ to the culture. Samples (about $150 \mathrm{mg}$ dry wt) were removed during growth and glutamine synthetase was isolated. It is possible from this experiment (Fig. 2) to follow the de novo 
Table 2. Incorporation of $\left[U-{ }^{14} C\right]$ isoleucine into glutamine synthetase octamer during enzyme reactivation

Yeast enzyme was deactivated by transferring a glutamate-grown culture to glutamine. The yeast was later transferred to medium containing glutamate and $\left[\mathrm{U}-{ }^{14} \mathrm{C}\right]$ isoleucine and samples were removed at intervals so that changes in the ${ }^{14} \mathrm{C}$ content of the enzyme could te measured during enzyme reactivation.

\begin{tabular}{|c|c|c|c|c|c|c|}
\hline $\begin{array}{l}\text { Time } \\
(\mathrm{min})\end{array}$ & $\begin{array}{l}\text { Specific } \\
\text { activity of } \\
\text { glutamine } \\
\text { synthetase } \\
\text { (units } / \mathrm{mg} \\
\text { protein) }\end{array}$ & $\begin{array}{l}\text { Total } \\
\text { protein } \\
\text { (mg) }\end{array}$ & $\begin{array}{c}\text { Total } \\
\text { enzyme } \\
(\mathrm{mg})\end{array}$ & $\begin{array}{c}{ }^{14} \mathrm{C} \text { in } \\
\text { glutamine } \\
\text { synthetase }(15 \cdot 4 \mathrm{~S}) \\
\text { (d.p.m./mg } \\
\text { protein) }\end{array}$ & $\begin{array}{c}10^{-3} \times{ }^{14} \mathrm{C} \text { in } \\
\text { mixed } \\
\text { proteins } \\
\text { (d.p.m. } / \mathrm{mg})\end{array}$ & $\begin{array}{c}\text { Total }{ }^{14} \mathrm{C} \\
\text { into } \\
\text { enzyme } \\
\text { (d.p.m.) }\end{array}$ \\
\hline 0 & 0.530 & 85 & $0.5 \mathrm{I}$ & 0 & 0 & 0 \\
\hline 20 & 0.910 & $92 \cdot 7$ & 0.95 & $5177^{*}$ & 2989 & 4918 \\
\hline 40 & $1 \cdot 380$ & $100 \cdot 7$ & $1 \cdot 57$ & 7112 & 6675 & I 145 \\
\hline 80 & $1 \cdot 410$ & 119.5 & $1 \cdot 89$ & 8950 & 12028 & 16987 \\
\hline
\end{tabular}

* Calculated from the d.p.m. under the glutamine synthetase activity peak on the sucrose gradient. The enzyme units were converted to $\mathrm{mg}$ protein to give d.p.m./mg enzyme.

synthesis of the enzyme when it is undergoing deactivation. Following the addition of glutamine to the culture the rate of enzyme synthesis is reduced to about $5 \%$ of its original value; since the kinetics of isotope incorporation are linear throughout, this reduction in the rate must have been effected within minutes of the elevation of the co-repressor pool. The relative rates of enzyme synthesis measured here correspond closely to the ones calculated from steady-state measurements in yeast growing on glutamate and glutamine (Ferguson \& Sims, 1974a).

\section{Incorporation of ${ }^{14} \mathrm{C}$ into glutamine synthetase during enzyme reactivation}

The enzyme was deactivated by transferring a glutamate-grown culture to glutamine $(2.8 \mathrm{~mm})$ for $60 \mathrm{~min}$. The yeast was carefully washed and resuspended into a medium containing glutamate $(2.8 \mathrm{~mm})$ and $\left[\mathrm{U}-{ }^{14} \mathrm{C}\right]$ isoleucine $(20 \mu \mathrm{Ci}, 0.15 \mathrm{mM})$; samples were removed at different intervals and processed as indicated earlier. The pattern of labelling observed during enzyme reactivation is shown in Table 2 . The rate of ${ }^{14} \mathrm{C}$-incorporation into glutamine synthetase is initially appreciably faster than into the total cell proteins, thus confirming directly that the restoration of enzyme level involves a very increased rate of de novo synthesis of the enzyme. Later, as the amount of the enzyme in the yeast approaches the steady-state level, the rate of enzyme synthesis is reduced progressively. The kinetics of isotope incorporation into the enzyme are linear and do not reveal an initial lag as might be expected if preformed tetramer were preferentially re-incorporated into the synthetase.

\section{The reversible reassociation of enzyme tetramers with diminished activity in the modulation of glutamine synthetase activity}

It seems possible that the rapid changes of synthetase activity which occur in response to alterations of ammonia availability (Sims \& Ferguson, 1972) may in part arise from a modification of the subunit organization of the enzyme. Direct observation of these changes in the living organism should be possible since we have established (Sims et al. 1974) that the synthetase-to-transferase activity ratio of normal enzyme is about 0.2 whereas in tetramers it is about 0.07 . A value of 0.17 was found in crude enzyme extracts obtained from yeast grown on a number of different amino acids. 

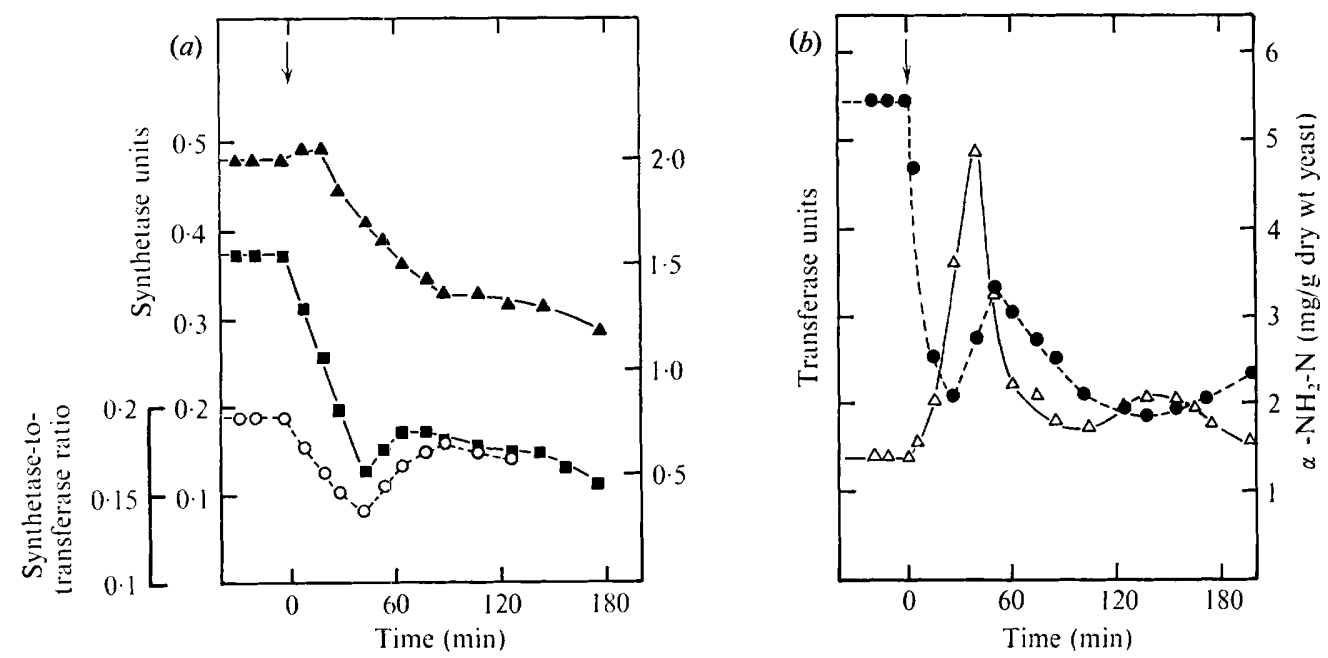

Fig. 3. Changes in (a) the specific activity of glutamine synthetase and $(b)$ the pools of glutamate and glutamine after a change in nitrogen source from glutamate to ammonia. Yeast was grown in a turbidostat in a medium containing a slight excess of glutamate ( $10 \mu \mathrm{g} \mathrm{N} / \mathrm{ml}$ ). At the time indicated by the arrows, ammonia was added directly to the culture $\left(0.15 \mathrm{~g} \mathrm{NH} \mathrm{NH}_{4} \mathrm{Cl} / 1\right)$ and the input medium was changed to one containing ammonia $(86 \mu \mathrm{g} \mathrm{N} / \mathrm{ml})$. The absolute ratio of the two enzyme activities can appear to vary slightly between experiments. This is because rates based on a single measurement of activity after 15 min incubation may not always be zero order, depending upon the level of activity assayed. This does not invalidate our conclusions, nor does it apply to enzyme originating from different nitrogen sources (Ferguson \& Sims, 1974b). $\square$, Synthetase activity; $\Delta$, transferase activity; $O$, synthetase-to-transferase ratio; $\mathbf{O}$, glutamate; $\triangle$, glutamine.

Yeast growing in a turbidostat on glutamate as sole source of nitrogen was subjected to a pulse with ammonia and at the same time the nitrogen source in the growth medium was changed to ammonia. Yeast samples were harvested at intervals during this transition and analysed for synthetase and transferase activity and for glutamate and glutamine content (Fig. 3). There was an immediate fall in synthetase activity on the addition of ammonia to the yeast, but this was not associated with a change of transferase activity. This indicates that, initially, the loss of synthetase activity is due almost entirely to the dissociation of the enzyme into tetramers with diminished synthetase activity. Subsequently both enzyme activities fell, indicating a net loss of enzyme had occurred. After about 40 min there was a relatively rapid rise in synthetase activity which coincided with the period when the pool of glutamate was being replenished. There are two reasons why it was unlikely that this increase in activity could be due to de novo synthesis of the enzyme. First, it occurred at a time when the pool of glutamine was elevated and we have already established that de novo synthesis of the enzyme is reduced under these conditions. Secondly, this increase in synthetase activity coincided with a slight fall of transferase activity. The oscillation in synthetase activity would thus seem to be due largely to enzyme reassociation. Measurements of in vivo rates of glutamine synthesis under these conditions (Sims \& Ferguson, 1974) showed a similar pattern of change: since rates of biosynthesis closely follow the pattern of synthetase activity but not of transferase, it would seem unlikely that enzyme tetramers are active in the living cell. This conclusion is consistent with our in vitro observations.

In another experiment (Fig. 4), yeast growing on ammonia was transferred to a medium lacking nitrogen and similar analyses were made on the enzyme over a period of time. A rapid increase (about $40 \%$ ) in synthetase activity occurred within a few minutes of transfer 


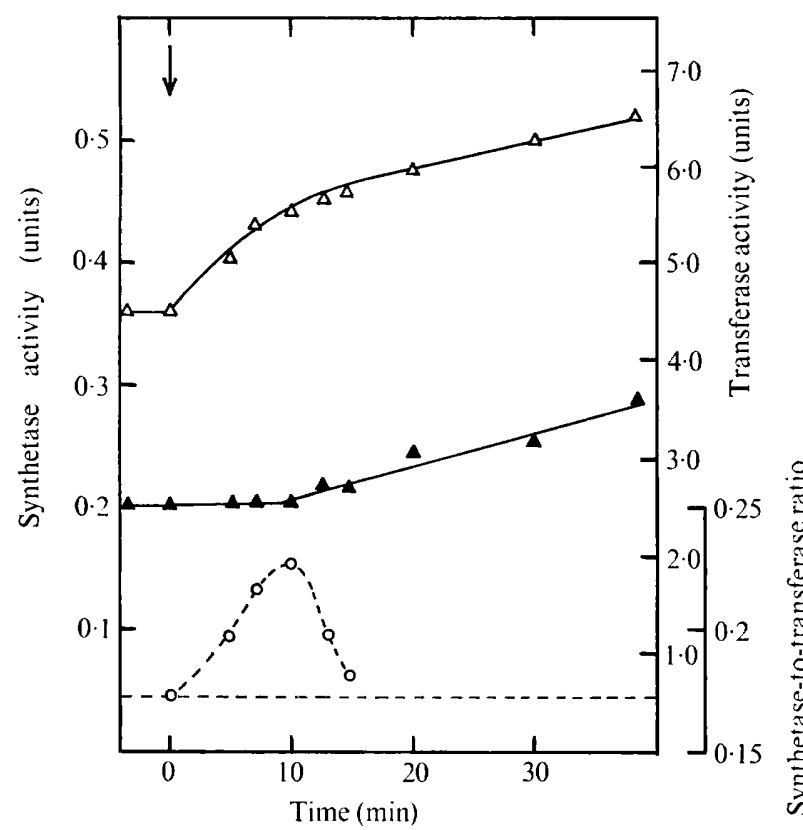

Fig. 4. Changes in the specific activity of glutamine synthetase after the transfer of yeast from complete medium to medium lacking a nitrogen source. Yeast growing on glucose-ammonia

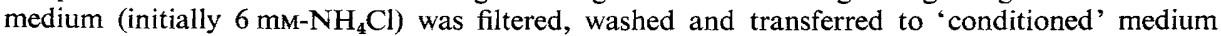
lacking nitrogen. $\triangle$, Synthetase activity; $\boldsymbol{\Delta}$, transferase activity; $O$, synthetase-to-transferase ratio. The broken line represents the synthetase-to-transferase activity ratio in a culture growing with glycine.

of the culture without any corresponding increase in transferase activity. The maximum synthetase-to-transferase activity realized (about 0.24) was almost twice that normally observed in crude enzyme extracts of yeast growing under steady-state conditions (Ferguson $\&$ Sims, $1974 b$ ). An increase in synthetase activity independant of transferase activity was also noted when yeast grown in glycine medium was transferred to a medium free of nitrogen; this implies that enzyme interconversion is a feature of yeast grown on other sources of nitrogen.

\section{The effect of various metabolic intermediates on the dissociation and reassociation of purified enzyme}

Experiments using sucrose gradient centrifugation to separate the products of dissociation from the active enzyme showed that metabolic intermediates can directly promote the interconversion of the enzyme. In some experiments purified enzyme was centrifuged in the presence of the particular metabolite in gradients which were subsequently examined for products of enzyme dissociation. In other experiments the ability of a metabolite to prevent enzyme dissociation was investigated by testing whether the enzyme remained associated in its presence in gradients containing I M-urea. In a third series of experiments enzyme tetramers were centrifuged with metabolic intermediates in gradients to find out whether reassociation of the enzyme had occurred. The results from all these experiments are given in Table 3. The recovery of yeast glutamine synthetase was not adversely affected by the presence of many of the metabolic intermediates tested. However, low concentrations of NAD, NADPH, and ATP caused significant dissociation of the enzyme as indicated by the 


\section{Table 3. Effects of metabolic intermediates on the dissociation and re-association of glutamine synthetase}

I. Centrifugation of purified enzyme in sucrose gradients containing various possible effectors

I mM-Glucose I-phosphate, I mM-glucose 6-phosphate, I mM-fructose I,6-diphosphate, 5 mM-pyruvate, 2 mM ADP, 2 mM-AMP, $50 \mathrm{~mm}$-D-glucosamine, $2 \mathrm{~mm}-3^{\prime} 5^{\prime}$-cyclic AMP, I mM-acetyl CoA, 2 mM-citrate, or

2 mM-DL-isocitrate

2 mM-NAD, 2 mM-NADPH or 2 mM-ATP

50 mM-Glutamine

2 mM-2-Phosphoenolpyruvate
A $100 \%$ recovery of enzyme as $15.4 s$ component

About $50-60 \%$ of enzyme recovered as $15.4 \mathrm{~s}$ component. Enzyme monomers were also detected

An $85 \%$ recovery of activity as the I 4 . I $s$ component. Monomers were also detected

Only $40 \%$ recovery of enzyme as I 4 . I $s$ component. Enzyme tetramers $(8 \cdot 4 s)$ and monomers detected in appreciable amounts

II. Centrifugation of purified enzyme in sucrose gradients containing $\mathrm{I} \cdot \mathrm{O} \mathrm{M}$ urea plus various effectors

Urea alone

I $00 \mathrm{~mm}$-Glutamate $+\mathrm{I} \mathrm{mm}-\mathrm{Mg}^{2+}$ or

$6 \mathrm{~mm}$-oxoglutarate $+\mathrm{I} \mathrm{mm}-\mathrm{Mg}^{2+}$

$6 \mathrm{~mm}-\mathrm{Oxoglutarate}$
About $50 \%$ recovery of activity; I $4.1 s$ and $8.4 s$ components recovered in approximately equal amounts

A $100 \%$ recovery of activity as a single $15.4 s$ component

About $60 \%$ recovery of enzyme activity peaking at about I I $s$. This indicated only slight protection against dissociation was afforded by this compound in the absence of $\mathrm{Mg}^{2+}$

III. Centrifugation of an extract containing enzyme tetramers in sucrose gradients containing various effectors

Control (no addition)

I $\mathrm{mM}-\mathrm{Mg}^{2+}$

I00 mM-Glutamate + I mM-Mge+

$6 \mathrm{~mm}-\mathrm{Oxoglutarate}+\mathrm{I} \mathrm{mm}-\mathrm{Mg}^{2+}$
Approximately equal amounts of 14.1 and $8.4 s$ present

About $200 \%$ increase in the $15.4 s$ found. A slight increase in the recovery of the $8.4 s$ component also evident.

A $400 \%$ increase in $15.4 s$ component observed together with a decrease in the $8.4 s$ component

An increase in the amount of $8.4 s$ component was observed. The amount of octamer was less than in the control experiment, indicating that oxoglutarate did not enhance re-association of the enzyme

formation of enzyme monomers. Glutamine promoted the conversion of native enzyme into its 'relaxed' form; this change was accompanied by only a small loss of enzyme activity. Phosphoenolpyruvate, in addition to facilitating conversion to the 'relaxed' enzyme, gave appreciable formation of enzyme tetramer. Rather more enzyme monomers were also observed under these conditions.

Glutamate and $\mathrm{Mg}^{2+}$ may be physiological effectors in enzyme modulation since they prevented dissociation of glutamine synthetase in I M urea. They also enhanced the reassociation of enzyme tetramers. 2-Oxoglutarate, although it could protect the enzyme from dissociation, did not promote its reassociation. The results indicated that fluctuations in $\mathrm{Mg}^{2+}$ concentration in the cell might be important in the modulation of the enzyme 


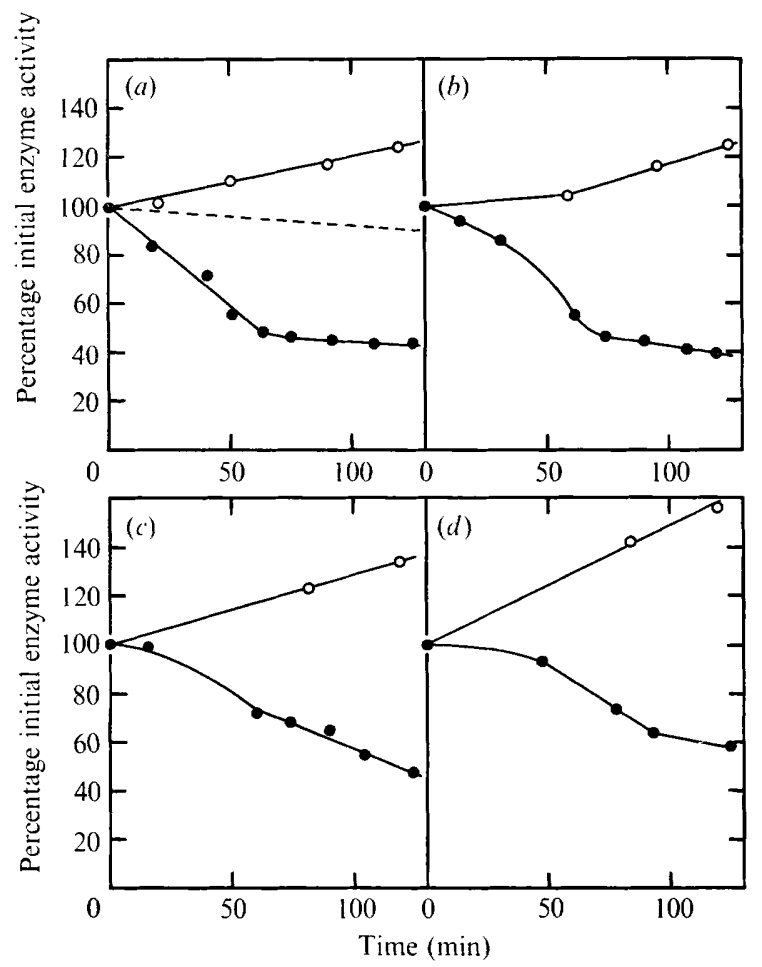

Fig. 5. Changes in the activity of glutamine synthetase and other enzymes following treatment of yeast with actidione. (a) $\alpha$-Glucosidase; $(b)$ nitrate reductase; $(c),(d)$ glutamine synthetase in yeast with fully de-repressed ( $c$, grown on glutamate) and partly repressed ( $d$, grown on nitrate) enzyme. $O$, Control culture;, culture treated with inhibitor. The broken line represents the mean rate of loss of enzyme calculated from protein turnover.

activity but our measurements show that intracellular concentrations of $\mathrm{Mg}^{2+}$ and $\mathrm{K}^{+} \mathrm{do}$ not change during inactivation of the enzyme (Box and Sims, unpublished observations).

\section{Studies with actidione on the possible involvement of proteolytic enzymes in the destruction of glutamine synthetase}

The conclusion (Ferguson \& Sims, I $974 b$ ) that enzyme inactivation was essentially an irreversible process was based on our inability to demonstrate any significant increase in synthetase activity following the transfer of organisms with deactivated enzyme to glutamate in the presence of actidione as the inhibitor of protein synthesis. In view of our present findings we re-investigated this problem and showed that failure of enzyme to reactivate under these conditions arose from the ability of actidione to activate mechanisms which promote the loss of several biosynthetic enzymes and to the activation of protein turnover. Yeast cells were grown in media containing different combinations of nitrogen and carbon sources (nitrate, glutamate, maltose and glucose). Following addition of actidione $(50 \mu \mathrm{g} /$ $\mathrm{ml}$ ) to the dividing culture, samples of yeast were removed for enzyme analyses. Changes in the activities of nitrate reductase, $\alpha$-glucosidase and glutamine synthetase were examined (Fig. 5). All three enzyme activities decreased after the addition of the inhibitor to the culture. A fall in protein was also observed (Fig. 6). The possibilities that either proteins were leaking from the organism or that extensive enzyme degradation was taking place in 

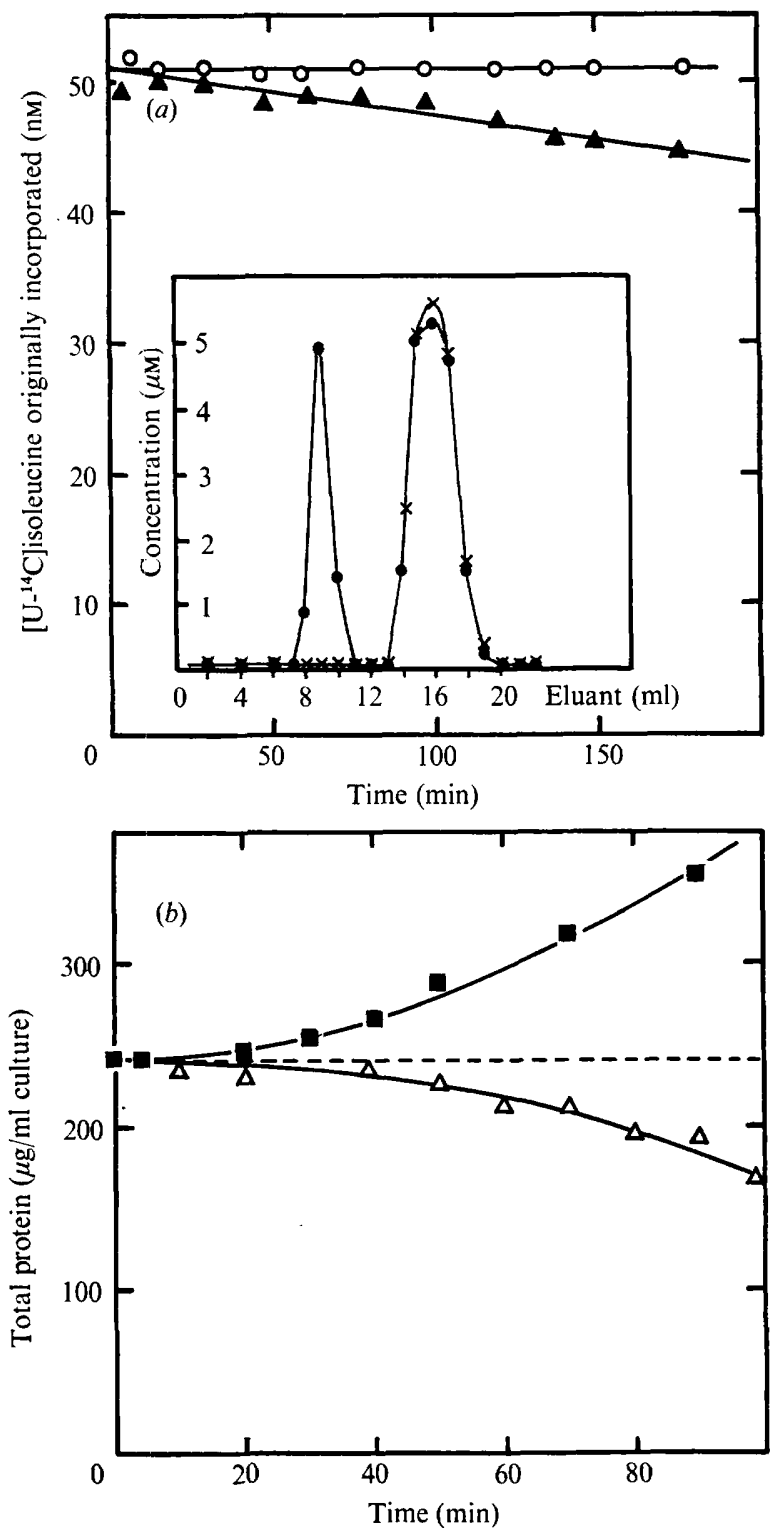

Fig. 6. Protein turnover in yeast in a complete growth medium containing actidione, detected by changes of protein content and the loss of protein-bound $\left[\mathrm{U}-{ }^{14} \mathrm{C}\right]$ isoleucine. $(a)\left[\mathrm{U}-{ }^{14} \mathrm{C}\right]$ isoleucine content of a yeast culture following treatment with the inhibitor. Inset: the chromotography of the medium derived from yeast after $3 \mathrm{~h}$ exposure to actidione on a column of Sephadex G-25. (b) Changes in the protein content of yeast. $O,{ }^{14} \mathrm{C}$ content $/ \mathrm{ml}$ control culture; $\boldsymbol{\Delta},{ }^{14} \mathrm{C}$ content $/ \mathrm{ml}$ culture exposed to actidione; 9 , elution of a standard mixture of bovine serum albumin and isoleucine; $\times,{ }^{14} \mathrm{C}$ content of column effluent; $\square$, total protein $/ \mathrm{ml}$ control culture; $\triangle$, total protein $/ \mathrm{ml}$ culture treated with inhibitor. 
the yeast were investigated in other experiments. Yeast growing on glutamate was pulsed with $\left[\mathrm{U}-{ }^{14} \mathrm{C}\right]$ isoleucine for $30 \mathrm{~min}$ and then allowed to grow in the presence of unlabelled amino acid for a further $60 \mathrm{~min}$ to ensure that the soluble pool of isoleucine was unlabelled. The yeast was resuspended in a complete medium containing $\mathrm{I} \cdot 0 \mathrm{~mm}$-isoleucine, and actidione $(50 \mu \mathrm{g} / \mathrm{ml})$ was added to half the culture. Samples of yeast were removed at various times from the two cultures and were extracted with $60 \%(w / v)$ ethanol prior to ${ }^{14} \mathrm{C}$ estimation. The results from this experiment (Fig. 6) show that whilst no fall in ${ }^{14} \mathrm{C}$ in the protein could be detected in the control, appreciable protein turnover could have occurred in yeast treated with actidione. Only the medium containing actidione contained significant amounts of radioactivity and this was chromatographed on Sephadex G-25 and on a Technichon TSM automatic amino acid analyser. The results (Fig. 6, inset) confirm that the loss of $\left[{ }^{14} \mathrm{C}\right]$ isoleucine from yeast treated with actidione arose from proteolysis. Thus whereas no labelled proteins were detected in the culture medium, gel filtration revealed that considerable amounts of radioactivity were associated with low molecular weight components. Ion exchange chromatography established that these ${ }^{14} \mathrm{C}$ counts were associated with isoleucine $(50 \%)$ and with several acidic peptides. Crude enzyme extracts obtained by treating yeast for $\mathrm{I} h$ with actidione were analysed on sucrose gradients and showed that the loss of glutamine synthetase activity was accompanied by an increase in enzyme monomers and tetramers.

These results lend no support to the idea that proteolytic enzymes participate directly in the control of the glutamine pathway. The rate of loss of glutamine synthetase is, initially, very much faster than the rate of protein turnover, and this implies that additional steps are involved in the deactivation of the enzyme. The fact that the products of dissociation of glutamine synthetase accumulate in treated cells, indicates that the destruction of enzyme monomers is slow in an organism with an activated proteolytic system. It is noteworthy that the rate of protein turnover measured in these experiments (over $5 \% / \mathrm{h}$ ) is comparable to that observed in bacteria starved of nutrients, a situation where proteolytic activity is known to be high (Mandelstam, I97I).

\section{DISCUSSION}

It is now possible to recognize three independent mechanisms concerned with the regulation of glutamine biosynthesis in food yeast: (i) a sensitive mechanism for controlling the de novo rate of enzyme synthesis; (ii) fine control of enzyme activity by the interconversion of active enzyme into tetramers with diminished catalytic activity; and (iii) enzyme destruction achieved by the irreversible dissociation of tetramers into inactive subunits.

'Coarse' control incorporates a mechanism of enzyme synthesis sensitive to changes in the amount of the end product glutamine. The isotope incorporation studies reported here are consistent with control of enzyme synthesis being affected at the level of enzyme translation. No delay of de novo enzyme synthesis was observed when yeast was transferred from glutamine to glutamate; had mRNA synthesis to be increased nearly 40 -fold to accommodate the increase in rate, a significant delay in the incorporation of isotope into protein would be expected. Again, after 'step down' from glutamine the de novo rate of enzyme synthesis was decreased immediately to a lower linear rate. There was no suggestion that the rate decayed exponentially as would be expected if the mRNA synthesized had a short but finite half-life (Kepes, I963).

The absence of direct feedback control on the irreversible pathway means that if an organism with de-repressed levels of glutamine synthetase receives an increased supply of ammonia, extensive glutamine synthesis involving diversion of 2-oxoglutarate, NADPH, glutamate 


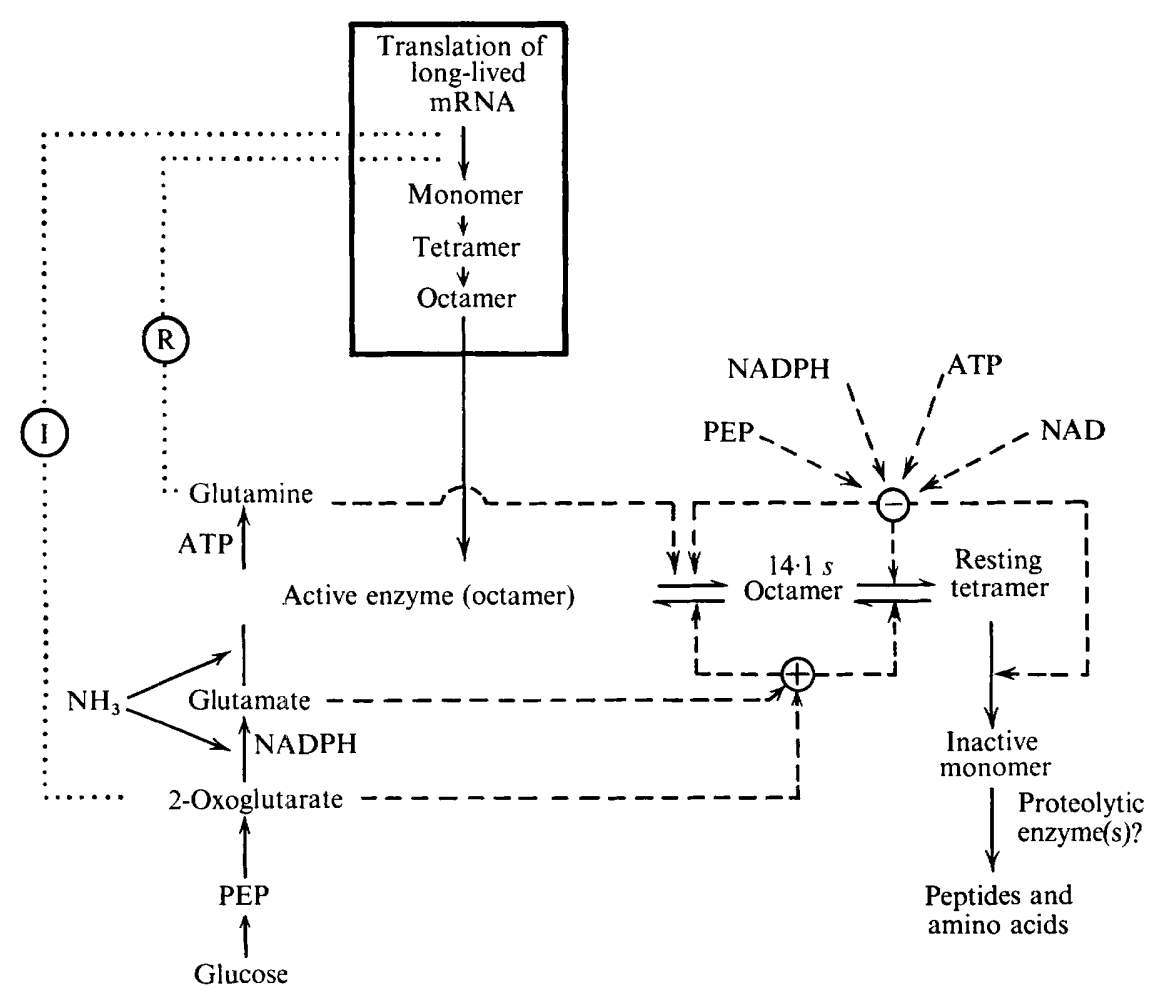

Fig. 7. A possible system of controls concerned with the regulation of glutamine biosynthesis in Candida utilis. This scheme interprets the enzyme labelling data and summarizes present knowledge of the action of a number of regulatory ligands on the activity and synthesis of glutamine synthetase. It is suggested that the enzyme is assembled from component monomers into an octameric protein consisting of two loosely bound half molecules and is subsequently transferred to a site where it functions. The biosynthetic activity of the enzyme at this second site is dependent upon the concentration of effectors in the cytosol and under normal conditions the enzyme is partly dissociated to provide a reserve of 'resting' enzyme. Enzyme inactivation involves the irreversible dissociation of these 'tight' enzyme tetramers. $\cdots$ (I) $\cdots$, Co-inducer of enzyme synthesis; $\cdots$ (B) $\cdots$ co-repressor of enzyme synthesis; - - $\oplus---$, regulatory ligands that can effect the re-association of 'resting' tetramers into active enzyme; $---\ominus---$, regulatory ligands that promote the dissociation of the active enzyme. PEP, phosphoenolpyruvate.

and ATP will follow. Clearly if this were to be sustained for a long period a large number of other biosynthetic and physiological processes would be affected. The development of other mechanisms of control ultimately safeguard the yeast against this possibility. 'Fine' control of glutamine synthetase appears to be based on a mechanism in which interplay between enzyme substrates and other metabolites not necessarily related to the pathway (metabolic interlock: Jenson, I969) determines the extent to which the enzyme is converted into a 'resting' form. This mechanism can increase or decrease the activity of the biosynthetic pathway and its operation provides an explanation for the oscillations in enzyme level observed when the nitrogen supply to the organisms is withheld or suddenly increased (Sims \& Ferguson, 1972). There is ample evidence to suggest that this mechanism can operate under widely differing conditions of growth. Analysis of crude enzyme extracts prepared from exponentially dividing cultures of yeast grown on a number of nitrogen sources revealed the presence of significant amounts of enzyme tetramers (Sims et al. 1974); 
in all instances the synthetase-to-transferase activity ratios of the crude enzyme preparations were comparable (Ferguson \& Sims, $1974 b$ ), indicating that the yeast managed to retain a similar reserve of tetramers. The presence of ' resting' tetramers may also be inferred from the data shown in Table $\mathrm{I}$. In two experiments involving pulse labelling a fall in the ${ }^{14} \mathrm{C}$ content of the enzyme octamer accompanied deactivation. The reduction in disintegrations was, however, less than in other proteins. Whilst in the latter instance continued synthesis of cellular proteins during deactivation can adequately account for the fall, the synthesis of the glutamine synthetase was very largely inhibited under these conditions and another explanation must be sought. One possible explanation is that during deactivation isotopic equilibration occurs between unequally labelled enzyme octamers and tetramers. This explanation requires that under steady-state conditions isotope is preferentially incorporated into enzyme octamers and a possible model to account for these observations is shown in Fig. 7.

Sufficient clarification of the identity of certain regulatory ligands and of the nature of their interaction with the enzyme has emerged from these studies to propose a plausible mechanism for control of enzyme activity (Fig. 7). Good agreement exists between in vivo and in vitro observations to suggest that glutamate can actively promote enzyme reassociation. There is also evidence to indicate that 2-oxoglutarate can stabilize the active form of the enzyme [there is now some evidence that it plays a similar role in the living cell and is probably a co-inducer of enzyme synthesis (Box and Sims unpublished)], and this could explain the earlier observation that continued catabolism of carbon intermediates was necessary to prevent enzyme deactivation (Ferguson \& Sims, 1974b).

Negative effectors are also implicated in the system of control. Thus 2-phosphoenolpyruvate is very effective in enhancing the dissociation of the enzyme, whilst structurally dissimilar compounds such as NAD, NADPH and ATP are also active. The observation that if 2-oxoglutarate or glutamate are present the enzyme can maintain its active configuration in conditions that normally lead to its complete dissociation, suggested a possible basis for enzyme modulation. The cumulative effect of negative effectors would ensure that the enzyme is normally dissociated but for the presence of 2-oxoglutarate and glutamate. Failure adequately to maintain the synthesis of these two compounds would then automatically produce enzyme deactivation and not require an elevation in the level of negative effectors. This idea is consistent with our present observations. Although we have repeatedly been able to demonstrate a reduction in the pool of glutamate or 2-oxoglutarate during enzyme deactivation, no corresponding rise in the level of negative effectors like 2-phosphoenolpyruvate has been observed.

Finally a comment concerning the destruction of glutamine synthetase. The isotope studies reported in Table $\mathrm{I}$ establish that only a limited return of ${ }^{14} \mathrm{C}$ label accompanies the in vivo reactivation of glutamine synthetase, with nearly $50 \%$ of the original enzyme not reutilized. The finding that enzyme monomers accumulate under these conditions and yet cannot be used directly to rebuild active enzyme suggests that the conditions in the living cell are such that once 'tight' tetramers dissociate the component subunits cannot be re-assembled. Presumably only later are they subjected to proteolytic attack and the amino acids so released incorporated into new protein.

This work was supported by the Science Research Council by grant B/SR/5II6. We thank Mr D. Walls for preparing the illustrations and for some skilled technical assistance, and Professor B. F. Folkes for his critical reading of the manuscript. 


\section{REFERENCES}

Ferguson, A. R. \& Sims, A. P. (I97I). Inactivation in vivo of glutamine synthetase and NAD-specific glutamate dehydrogenase: its role in the regulation of glutamine synthesis in yeasts. Journal of General Microbiology 69, 423-427.

Ferguson, A. R. \& Sims, A. P. (1974a). The regulation of glutamine metabolism in Candida utilis: the role of glutamine in the control of glutamine synthetase. Journal of General Microbiology 80, 159-171.

Ferguson, A. R. \& Sims, A. P. (I974 b). The regulation of glutamine metabolism in Candida utilis: the inactivation of glutamine synthetase. Journal of General Microbiology 80, I73-185.

Folkes, B. F. \& SIMS, A. P. (1974). The significance of amino acid inhibition of NADP-linked glutamate dehydrogenase in the physiological control of glutamate synthesis in Candida utilis. Journal of General Microbiology 82, 77-95.

JENSON, R. A. (I969). Metabolic interlock. Regulatory interaction exerted between biochemical pathways. Journal of Biological Chemistry 244, 2816-2823.

KePES, A. (1963). Kinetics of induced enzyme synthesis. Determination of the mean life of galactosidasespecific messenger RNA. Biochimica et biophysica acta 76, 293-309.

MANDELSTAM, J. (197I). Recurrent patterns during development in primitive organisms: control mechanisms of growth and differentiation. Symposia of the Society for Experimental Biology 25, I-26.

Nason, A. \& Evans, H. J. (1953). Triphospho-pyridine nucleotide-nitrate reductase in Neurospora. Journal of Biological Chemistry 202, 655-673.

Sims, A. P. \& Ferguson, A. R. (I972). The role of enzyme inactivation in the regulation of glutamine synthesis in yeast: in vivo studies using ${ }^{15} \mathrm{~N}$. 6 . Wissenschaftliche Konferenz der Gesellschaft Deutscher Naturforscher and Ärzte, Rottach-Egern. In Second International Symposium on Metabolic Interconversion of Enzymes, pp. 26I-267. Edited by O. Wieland, E. Helmreich and H. Holzer. Berlin, Heidelberg and New York: Springer-Verlag.

Sims, A. P. \& Ferguson, A. R. (1974). The regulation of glutamine metabolism in Candida utilis: studies with ${ }^{15} \mathrm{NH}_{3}$ to measure in vivo rates of glutamine synthesis. Journal of General Microbiology 80, $143-158$.

Sims, A. P., Toone, J. \& Box, V. (I974). The regulation of glutamine synthesis in the food yeast Candida utilis: the purification and subunit structure of glutamine synthetase and aspects of enzyme deactivation. Journal of General Microbiology 8o, 485-499. 